\title{
Guidelines for Conducting a Survey of the Use of Safety Belts and Child Safety Seats
}




\title{
GUIDELINES FOR CONDUCTING A SURVEY \\ OF THE USE OF SAFETY BELTS \\ AND CHILD SAFETY SEATS
}

\author{
Peter N. Ziegler \\ Office of Driver and Pedestrain Research \\ Research and Development \\ National Highway Traffic Safety Administration \\ Washington, D.C.
}

May 1983 
TABLE OF CONTENTS

Introduction $\ldots \ldots \ldots \ldots \ldots \ldots \ldots \ldots \ldots \ldots \ldots \ldots \ldots$

I. Selection of Data Sampling Sites.................

A. Traffic Site Selection....................

B. Shopping Center Selection..................

II. Data Sampling Procedures.......................

A. Sample Size...........................

B. Sampling Procedures.......................

C. Data Analysis $\ldots \ldots \ldots \ldots \ldots \ldots \ldots \ldots \ldots \ldots \ldots \ldots$

III. Collection of Occupant Protection Usage Data..........8

A. Data Requirements.....................

B. Driver Survey Requirements.................

C. Passenger Survey Requirements................

D. Training Requirements.....................

IV. Instructions For Data Collectors...............1

A. Collection of "Driver" Data.................11

B. Collection of "Passenger" Data.................

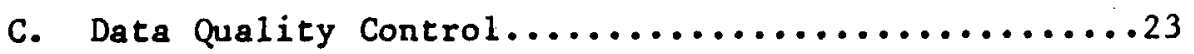


This manual provides guidance for conducting observational surveys to assess the usage of safery belts and child safety seats. Observation surveys are generally included as one aspect of evaluations to assess the effectiveness of programs to increase the usage of occupant protection systems. Other evaluation aspects can include telephone surveys to assess peoples attitudes and use of restraints. Observational surveys are desirable because they are a direct measurement of occupant protection usage as opposed to "claimed" usage.

This manual is divided into four sections. Section I describes how to select the traffic sites and shopping centers to be used as observation points. Section II presents sampling procedures that can be used to obtain the desired data and includes suggestions for data analysis. Section III recommends specific data collection requirements for driver and passenger studies along with some general training guidelines. Section IV, which can be detached from the manual for purposes of reproduction, provides specific data collection instructions for observers along with sample data forms.

The design and data collection procedures presented herein are offered as a basic foundation upon which individual community evaluation studies can be structured. For example, the manual recommends that drivers be observed at traffic sites and that children be observed at shopping centers. This recommendation is made because only about 1 percent of cars at traffic intersections have an infant passenger and about 4 percent of cars have a toddler passenger, whereas the frequency of these children in cars at shopping centers is about two to three times greater. However, if no suitable shopping centers are available, observation of drivers and children will have to be made at traffic intersections. In that case procedures for conducting observations will need to be selected from those sections of the manual specific to drivers and children passengers. It is important that the procedures are "pilot-tested" before observers are trained and sent out to collect data.

Special precautions should be taken to assure the safety of survey personnel. Police agencies should be informed of the study and the traffic sites and times when observers will be working. In addition, the use of safety vests and name tags help give the observers an "official" look. Use of a "to whom it may concern" letter describing the study and signed by a high level city/state official can be very helpful if the observer's credentials are questioned.

It is recommended that a "TRAFFIC SURVEY" sign be placed on the back of the clipboard used to collect data. This sign will reduce the incidence of people asking questions and reduce concerns by occupants about why an observer is looking into their car.

Once a study is initiated, a large amount of data may be generated. Arrangements for the tabulation, storage and analysis of data should be made before any data collection is begun. Consultation with someone experienced in social science research and statistical methods in the course of planning the study is strongly recommended. The States' highway safety agencies or faculty from local colleges could be asked to provide this guidance. 
The various tasks associated with conducting a survey are listed below in a proposed sequential order. Detailed.descriptions of most of these tasks are presented in the main text of the manual.

1. Find an individual knowledgeable in statistical techniques to assist in planning the survey

2. Identify individual responsible for tabulating and analyzing data

3. Set goals for increased usage

4. Select the locations for collecting data

5. Decide exactly what data is needed, (i.e. belt use by drivers)

6. Determine the times of day that observations will be made

7. Estimate how many observations are needed for the survey

8. Develop data collection forms

9. Discuss survey with police

10. Test the data collection procedures by going to selected sites and collecting use data

11. Revise plans as necessary

12. Recruit data collectors

13. Assemble materials for data collectors (data forms, identification, badges, clip boards, etc.)

14. Conduct training for data collectors

15. Develop and implement a schedule for monitoring data collection

16. Collect data

17. Tabulate and analyze data

18. Report on results 
I. SELECTION OF DATA SAMPLING SITES

Data collection sites need to be selected so that occupant protection system usage rates can be measured before promotional efforts are initiated. Once the program is underway, usage would be measured again at these same data collection sites. Differences detected between usage rates obtained during these measurement periods would help assess the effectiveness of the program. Statistical analyses can be employed to determine whether any observed changes in usage were due to chance.

It is essential that. the evaluation plan assure that the sample of people to be observed is representative of the population that is to be affected by the program. This can be ensured by selecting those collection sites where the target population can be observed. The first step in developing a data sampling plan is to identify the target population that is to be affected by the program. The second step is to determine the best data collection sites so that a reasonably representative sample of the target population can be observed. For example, if the program is directed at increasing child safety seat usage, the survey may be restricted to children leaving shopping centers because it is impractical to observe children elsewhere. If an increase in child seat usage is detected at the selected shopping centers, it cannot be assumed that all children in the same community were affected by the program. Extreme caution should be taken in attributing measured changes to wider populations than those from which the sample is drawn.

If the purpose of the study is to detect changes in driver usage of safety belts, observation of all drivers at all times of the day and night would be the ultimate approach. However, for practical reasons this cannot be done. Observations at night are not feasible and observing all drivers in the community even during the day is out of the question. Therefore, most studies are forced for practical reasons to collect data on only a small but carefully selected sample of the population of interest.

The procedures presented below are designed to allow the selection of observation points that provide some reasonable degree of representativeness for drivers using primary roads in daytime traffic within a city. However, these procedures may not be appropriate for all studies. If the program is designed for a specific segment of drivers or passengers and/or for people in a specific section of a city, modification of selection procedures presented in this manual will be necessary. For example, if the program is for high school students, traffic sites close to the high schools as opposed to sites all over the city should be selected. It is critical that once data collection sites are selected, data be collected at only those sites during the study. Another important consideration is that an attempt be made to sample people of various socio-economic levels because this factor has been shown to be highly correlated with safety belt usage. 
A. Traffic Site Selection

To obtain safety belt usage data, it is recommended that sampling be conducted at road intersections and freeway exits controlled by traffic signals.

In a small community where there are only a few signalized intersections, data could be collected at all of these sites. However, because most cities have far too many signalized intersections to make it practical to cover all of them, some type of sampling plan is required. The objective of the sampling plan generally is to select intersections that will provide for representatation of: (a) type of roadway such as freeways and primary roads, (b) sites where there is heavy traffic in order to assure adequate sample size, and (c) sites that will include people from different socio-economic levels. It is possible that some programs will be designed to cover specific sections of the city. In this case, the procedures suggested in this manual should be applied to those sections of the city that are of interest.

The first step in selecting the specific intersections is to draw a grid of intersecting lines across a map of the community so as to divide it into small squares. Each square should be large enough to include several road intersections. The use of primary as opposed to secondary road intersections is suggested because of the much greater traffic flow. A greater number of cars stopping at intersections will allow a much more cost-effective data collection effort. Next, the squares that are in areas that are strictly residental, include a park or a lake, contain no primary road intersections or freeway exits, encompass areas of high crime, or pose other data collection problems should"be eliminated. Theremaining squares should be divided into "sections" based on socio-economic level and numbered. At this point a table of random numbers (available through a college professor or a high school math teacher) may be used to. select an appropriate number of squares from within each of the "sections."

Once the squares are identified, one primary road intersection or freeway exit should be selected from within.each square. This can be accomplished by locating all the major intersections within each square and assigning each intersection or freeway exit a random number. Next, a site visit should be made to intersection number 1 in a particular square to determine if it meets established criteria. If not, proceed to intersection number 2 on the 1 ist and so on until an acceptable site is found. This procedure should be followed for each square selected. The selection criteria should include intersections or freeway exits that:

1. are controlled by traffic signals or stop signs (traffic signals generally provide longer viewing time for observers than stop signs);

2. have a safe curb to stand on and provide a good vantage point for observing vehicle occupants; 
3. provide sufficient traffic flow so that at least one car will stop for every change of the traffic signal;

4. have no road construction in progress that would interfere. with traffic flow;

5. are not located in a high crime or potentially dangerous area; and

6. are not congested with trucks or buses.

B. Shopping Center Selection

The use of shopping centers is recommended for the collection of data on child seat usage as opposed to using traffic intersections because of the larger proportion of children in cars using shopping centers. Other sites could be used such as day care centers, childrens'medical facilities, and similar places. However, these sites probably will provide a less representative sample of children in the community than shopping centers. In addition, these sites most likely will provide a much smaller sample of children than a shopping center. Shopping centers from different areas of the community should be included so as to sample a cross section of various socio-economic classes. A few well selected shopping centers should be sufficient.

To begin the selection process, a list of all the major shopping centers in the community should be prepared. Next, all centers should be visited during busy periods in order to (a) estimate the number of children that might be observed over some specific period of time, (b) select the exits with the greatest traffic flow, (c) estimate the socio-economic status of the center's customers if this information cannot be obtained elsewhere and, (d) determine if there are good vantage points for observational purposes. Based on this review and any other criteria that have been established, shopping centers that best fit the requirements of the survey should be selected. Observations should be scheduled on days and at times when the shopping centers are the busiest.

II DATA SAMPLING PROCEDURES

It is critically important that the survey be structured so as to distinguish between an increase in usage resulting from program activities as opposed to an increase that could be attributable to chance alone. Consultations with someone experienced in social science research on the issues of sample size, procedures, and data analysis are strongly recommended before the survey is initiated. 
A. Sample Size

To determine the success of a program to increase occupant protection system usage, it is necessary to gather data on a sufficient number of vehicles, drivers and/or passengers both before and after the program is launched. Programs based exclusively on educational and informational approaches rarely produce dramatic increases. However, incorporation of other features into the program, such as incentives and rewards to induce behavioral change, offer the prospect for greater success. Nevertheless, in establishing the requirements for observational surveys, it is advisable to base the size of the sample on a conservative estimate of increased usage.

The table below depicts the post-program usage rate as a function of sample size and pre-program usage rate. For a given sample size and pre-program usage rate, the post-program usage rate shown is the minimum value that will produce a significant increase (greater than zero) at the 0.05 significance level. The sample sizes given are based on the assumption that they are representative of the affected target population.

TABLE 1

\begin{tabular}{rcccccc}
\hline Sample & \multicolumn{6}{c}{ Pre-Program } \\
\hline Size & $10 \%$ & $15 \%$ & $20 \%$ & $30 \%$ & $40 \%$ & $50 \%$ \\
\hline 200 & $17.5 \%$ & $23.5 \%$ & $29.0 \%$ & $40.0 \%$ & $50.5 \%$ & $60.5 \%$ \\
500 & $14.4 \%$ & $20.0 \%$ & $25.4 \%$ & $36.2 \%$ & $46.4 \%$ & $56.4 \%$ \\
1,000 & $12.9 \%$ & $18.4 \%$ & $23.8 \%$ & $34.5 \%$ & $44.5 \%$ & $54.5 \%$ \\
\hline
\end{tabular}

As an example, suppose the pre-program usage rate for drivers was $10 \%$ and the pre- and post-program survey sample sizes were 500 . An increase in usage to at least $14.4 \%$ would would be necessary to demonstrate a significant increase. However, with a sample size of 1,000 , an increase of 2.9 percentage points would be statistically significant and one could say with $95 \%$ confidence the post-program usage rate was greater than the pre-program usage rate.

In order to use Table 1 , some knowledge of pre-program usage rates is necessary. Most likely, this information will not be available for the comnunity of interest. Consequently, it is necessary to collect preliminary data to obtain some idea of the community's usage rates. It is suggested the during the pilot testing of the procedures, the selected data collection sites be used to collect data on about 500 drivers and/or about 100 children. This data cannot serve as the "before" or "baseline" usage rates but will provide a rough estimate so that Table 1 can be utilized in determining the minimum sample size. 


\section{B. Sampling Procedures}

Day of week and time of day have not been shown to be consistently correlated with safety belt usage rates and probably are not of sufficient interest to be assessed in most studies. Therefore, these factors are not described in the sample design plan. However, observations should be conducted during hours throughout the day as well as during different days of the week. In addition, it is recommended that observations be made during the same time period every time data is collected at a particular site. This will increase the likelihood that the same people will be observed before, during and after the program. Surveys should be confined to daylight hours when there is sufficient natural light to permit clear vision into car interiors.

Past experience in collecting data indicates that about one or two hours are required to obtain a sample of 50 to 100 cars at each traffic site. Based on this rate, and the number of traffic sites selected, an estimate of the amount of data collection time needed to meet sample size requirements can be made. Experience also indicates that there are likely to be variations in belt usage between different traffic sites. Consequently, it is preferable to conduct observations at a large number of traffic sites for shorter time periods as opposed to fewer sites and longer observation periods. For example, selecting 100 sites and making observations at each for one hour is more appropriate than selecting 20 sites and observing for 4 hours at each site.

The length of time needed to collect the data for each sampling period will depend on the necessary sample size, the number of sites selected and the availability of observers. Many of the observers may be volunteers and have limited time available to make observations. To meet these requirements it is not unreasonable to collect data for more than one month. However, care must be exercised to assure that "before" observations are completed before any word of the program is released to the public. Observation at shopping centers is most efficiently done during the later part of the week from late mornings through late afternoon. Because of the low occupancy rate of children in cars, it will be more difficult to observe a sufficient number of children as compared to drivers. Consequently, it probably will be necessary to conduct observations for several days at each shopping center to obtain a sufficient amount of data for each of the sampling periods.

It is critically important that each data sampling period (before, during and after the program) follow identical data collection procedures. 
C. Data Analysis

The extent to which statistical analyses can be performed wili depend on the range and detail of the data collected. These questions should be addressed during the course of preparing the study design, preferably in consultation with someone experienced in social research methods. As a minimum, the gross change in usage rates before, during and after the program is concluded, should be determined. Such an analysis simply requires that the number of users in a sample group(s) be expressed as a percentage and compared over time. After these calculations have been made, Table 1 can be used to determine whether any increase in usage was statistically significant.

\section{COLLECTION OF OCCUPANT PROTECTION SYSTEM USAGE DATA}

A. Data Requirements

A decision should be made during the planning phase of the study on what information is essential and what data are of interest but not really necessary. As the demand for more types or categories of data is increased, there will be a corresponding increase in the difficulty of the data collection requirements for the observers. The more difficult the task for the observer, the greater the risk of obtaining inaccurate data. In addition, more categories of data will increase the amount of time needed for training the observers.

The remainder of this manual presents an approach that allows for the collection of essential restraint system usage information using observation techniques that are practical and reasonably easy for part-time or volunteer observers to utilize.

B. Driver Survey Requirements

For the "driver" survey, observations should be made of driver safety belt usage and, if the data collectors are sufficiently well trained, right-front seat passengers can be included. Observations should be made of cars stopped for traffic signals at the selected primary road intersections. From the curb lane it is more difficult to see the lap belt being used by the passenger than by the driver. However, with a little more effort on the part of the observer, front seat passenger data can be obtained. Note that most of the cars at traffic intersections will not have passengers.

It.is recommended that protection system usage data for small children and for occupants in the back seat not be collected at traffic intersections. Observation of protection system use for all occupants in each car is too difficult a task for most observers. In addition, collecting data on small children is more efficiently obtained at shopping centers. Collection of data on these passengers will be discussed in the next section. 
C. Passenger Survey Requirements

For the "passenger" survey, data would be obtained on just passengers in cars stopped for traffic signals entering or leaving shopping centers. Observation of children in safety seats is a relatively easy task unless assessment of correct and incorrect ise of these devices is included. Correct use of child safety seats requires that a safety harness or a shield or both are appropriately used to secure the child in the device. Many seats require a tether strap. to secure the child seat to the car. Determination of whether or not the seat observed requires a tether is very difficult and it is even more difficult to see if the tether is attached or correctly anchored to the car. Also, child seats require a specific routing of the car safety belt through the child seat to secure it to the car. Being able to see whether the car belt is fastened through the child seat is difficult especially when looking at these devices in the back seat of a car. Collecting accurate data on these modes of correct/incorrect usage would require stopping cars for inspection and/or studying cars in parking lots. Using such techniques to assess correct/incorrect use of child seats is probably beyond the scope of most evaluation studies. Consequently, procedures for assessing correct and incorrect usage are not described in this manual and will be treated in a separate document. The emphasis of this manual is to provide instructions for assessing the percent of children in a safe child seat only.

Trying to observe child seat usage as well as belt use by other passengers at the same time is a very difficult task for observers. However, this task can be made easier by providing observers with "priority" instructions. Because there are so few infants and toddlers in cars, the first priority of the observers should be to collect data on these age categories. For example, if the car under observation has an infant or toddler as well as other older passengers present, data on the younger passengers would be collected first. Data would not be recorded for the older

passengers unless there is ample time to accurately determine their use of safety belts. For cars without infants or toddlers, passenger belt usage could be collected for subteens (age 5-14), teens (age 15-19) and adults (age greater than 19). These age categories have been found to be reasonably easy for observers to identify.

D. Träining Reguirements

As the types or categories of data to be collected are increased there will be a corresponding increase in the time it takes to train observers. A recommended training procedure is to start with a "classroom" setting to explain the study followed by some "on-site" supervised data collection. More specifically, during the classroom period the background and the purpose of the study 
should be explained. The responsibilities of the observers in regard to completeness and accuracy of data should be stressed. The data collection forms should be discussed in detail including exactly how the data are to be collected and controlled for quality. Providing the observers with an Instruction Manual similar to the last section of this manual would be helpful.

It is important to have some demonstration material during the classroom period such as slides of people in cars belted and unbelted as well as pictures of child seats. Having a sample of different types of child seats and a large doll is very helpful in explaining the usage of these devices.

During the on-site training period the observer should collect data under the direct supervision of an instructor. Once observers becomes somewhat proficient, they can practice on their own. It will take several hours of practice for an observer to feel comfortable and become familiar with the data collection procedures and forms. Each observer should be monitored frequently as the practice continues.

After about an hour of practice, both the observer and instructor should observe the same cars at the same time and collect data independently. After each observation is recorded any differences between the data collected by the supervisor and the observer should be discussed and appropriate corrections made. Trying to train more than two observers on-site at the same time is too difficult and is not recommended. A reasonable ratio for training is two observers for each supervisor. Once the initial training is completed it is suggested that each observer spend several hours to a couple of days collecting data on their own with only occasional supervision. The data collected should be checked for neatness, clarity and to the extent possible, accuracy.

After the training program, the observer should be able to collect accurate data. However, on-site spot checks are recommended as a quality control measure. In addition, the completed data sheets should be reviewed carefully during the entire data collection period for any deviations in the data among observers. Obvious discrepencies in the data should be investigated promptly and additional training provided as necessary. 
IV. INSTRUCTIONS FOR DATA COLLECTORS

A. Collection of "Driver" Data

1. Eligible Vehicles

Only privately-owned passenger cars and station wagons licensed in the State (or where possible the city or county) in which the survey is being conducted are eligible for observation. Trucks, vans, or passenger cars used for commercial purposes, such as taxi cabs and marked company cars should not be included.

If more than one car stops for the traffic signal, observations should begin with the second car. (This eliminates the bias of collecting data on mostly conservative drivers who generally are on the first to stop when a traffic signal changes). If time permits make observations on the third car and fourth car etc. until the light changes and traffic begins to move. If only one car stops, observe that vehicle. Any vehicle that stops for a stop sign can be observed.

\section{Observation Techniques}

At intersection locations, position yourself on the street with the greatest flow of traffic. The greatest flow should be toward the inner city, in the morning, as people go to work; and away from the city, in the afternoon, as people go home. If in doubt, the busiest corner or the one that most easily allows data to be recorded each time the traffic light turns red should be used.

Observers should stand on the curbside at the selected stop light intersection. At most locations there will be more than one lane of traffic traveling in the same direction. Observations are restricted to cars in the curbside lane. Do not enter the street to record data on cars in other lanes.

The interior of the car must be observed to record the information needed. This is very important when trying to see if the lap belt is fastened on older cars (1964-73 model years) that are not equipped with combination lap-and-shoulder belts. Making observations in newer cars equipped with combination lap-and-shoulder belts is easier because the shoulder portion of the belt is quite visable when being worn. These observations will take place from the passenger's side of the car. In order to record the information needed, it may be necessary to peer into the window of the car to examine the interior of the car and its occupants. Under these circumstances, it is important that the sign on your clipboard that reads "Traffic Survey" be visible to the occupants. 
Don't "guess," if you are not sure about your observation of restraint usage do not record anything and go on to the next car.

Only after all data on the observed car has been fully recorded on the form should your attention be directed to another vehicle. Accuracy is more important than the number of cars observed. While the traffic light is green, the last recording of data can be checked before the next set of cars stops. As many vehicles as possible should be observed but not at the sacrifice of accuracy.

3. Data Collection Form

The next page presents the form for recording driver and front passenger safety belt usage data. 
DRIVEK SURVEY OBSERVATION FORM

$\begin{array}{lll}\text { 1. Observer } & \text { 2. Date: } \\ \text { 3. Location: } & \text { 4. Ereeway exit? } \\ \text { 5. Start Time: } & \text { 6. End Time:_AM-PM } & \text { AM-PM }\end{array}$

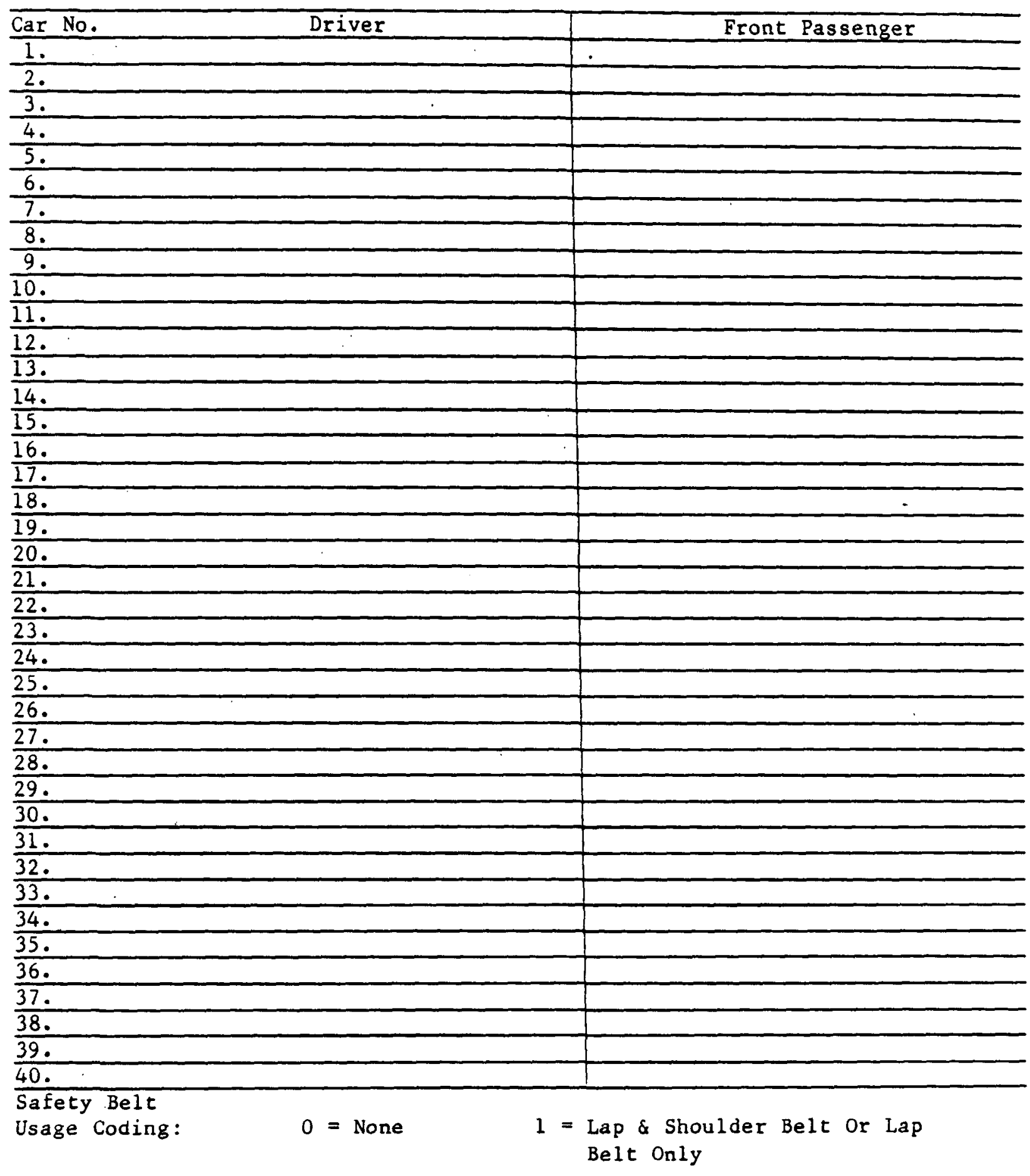


4. Instruction for Filling in Driver Survey Observation Form

a. General Information

The top portion of each form provides important

information and should be completed for each sheet used to obtain data.

o Observer: Write in your name.

- Date: Write in the month, date, and year. For example write in $7 / 4 / 83$ for July $4,1983$.

- Location: Write in the names for the intersecting streets and a landmark to identify the corner on which you are standing.

- Freeway: Check only if the site is a freeway exit.

- Start \& End Time: Specify the hour and minutes, and circle $A M$ or $P M$ for the start and end of the data collection using that survey form.

b. Recording Observation Data

Complete one line on the form for each vehicle observed. Start with the second car stopped for the stop light. Obtain an additional observation during the red light if time permits. If only one car stops at the light, observe that car.

There are two possible code categories for describing the use of safety belts. These Are:

- None (Code 0$)$

If you are certain the belts are not being worn then record this as code " 0 ".

- Lap and Shoulder Belt or Lap Belt Only (Code 1)

This means that a positive observation has been made that a safety belt is being worn, where the lap belt is across the driver's waist or/and the shoulder harness is across the shoulder. 
B. Collection of "Passenger" Data

1. Site Selection

Upon arrival at the assigned shopping center, you may need to look over shopping center layout to identify the best locations for data collection. This is only necessary if the specific exit has not already been identified. Important considerations are :

- Safety - is there a safe place to stand at each of the shopping center exits and entrances.

- Traffic Flow - select the exits that provide the greatest flow of traffic. Sites where cars become backed up are ideal if there is a safe vantage point from which occupants can be easily seen.

- Speciality shop locations within the shopping center - are there stores in the shopping center that cater to infants and small children (such as toy stores, maternity shops, etc.) and, if so, does a particular exit favor clientele from these shops.

2. Observation Hours

Probably the best hours for data collection are between the hours of 11:00 AM and 5:00 PM. Observations should be made at times when children are most likely to be in cars. Be sure to find out when (hours and days of the week) the shopping center is open for business.

\section{Eligible Vehicles}

Only privately owned passenger cars and station wagons are eligible for this survey. Trucks, or vehicles used for commercial purposes, such as taxi cabs and marked company-owned cars should not be observed. Also, cars with out-of-state license plates should not be included. 
4. Observation Techniques

Observers should stand on the curbside at the exit or entrance to the shopping center with the greatest flow of traffic. At locations where there is more than one lane of traffic traveling in the same direction, observation should be made of only the cars in the closest lane. Do not go out into traffic to observe cars in any other lanes.

Observations will be made from the passenger's side of the car. In order to record the information needed, it may be necessary to peer into the window of the car to determine restraint usage. When this is necessary, make sure that your clipboard sign ("Traffic Survey" sign) is visible to the occupants.

Target observations will be vehicles with one or more passengers in the car. For example, when several cars stop at a traffic light, select the car with the most passengers, particularly those with infants and toddlers.

\section{Data Collection Form}

The following page presents the form for collecting data on passenger occupant protection system usage. 
1. Observer:

3. Shopping Center Name:

5. Start Time:

$A M-P M$
2. Date:

4. Location:

(Street Name)

6. End Time: $A M-P M$

PASSENGER AGE GROUP

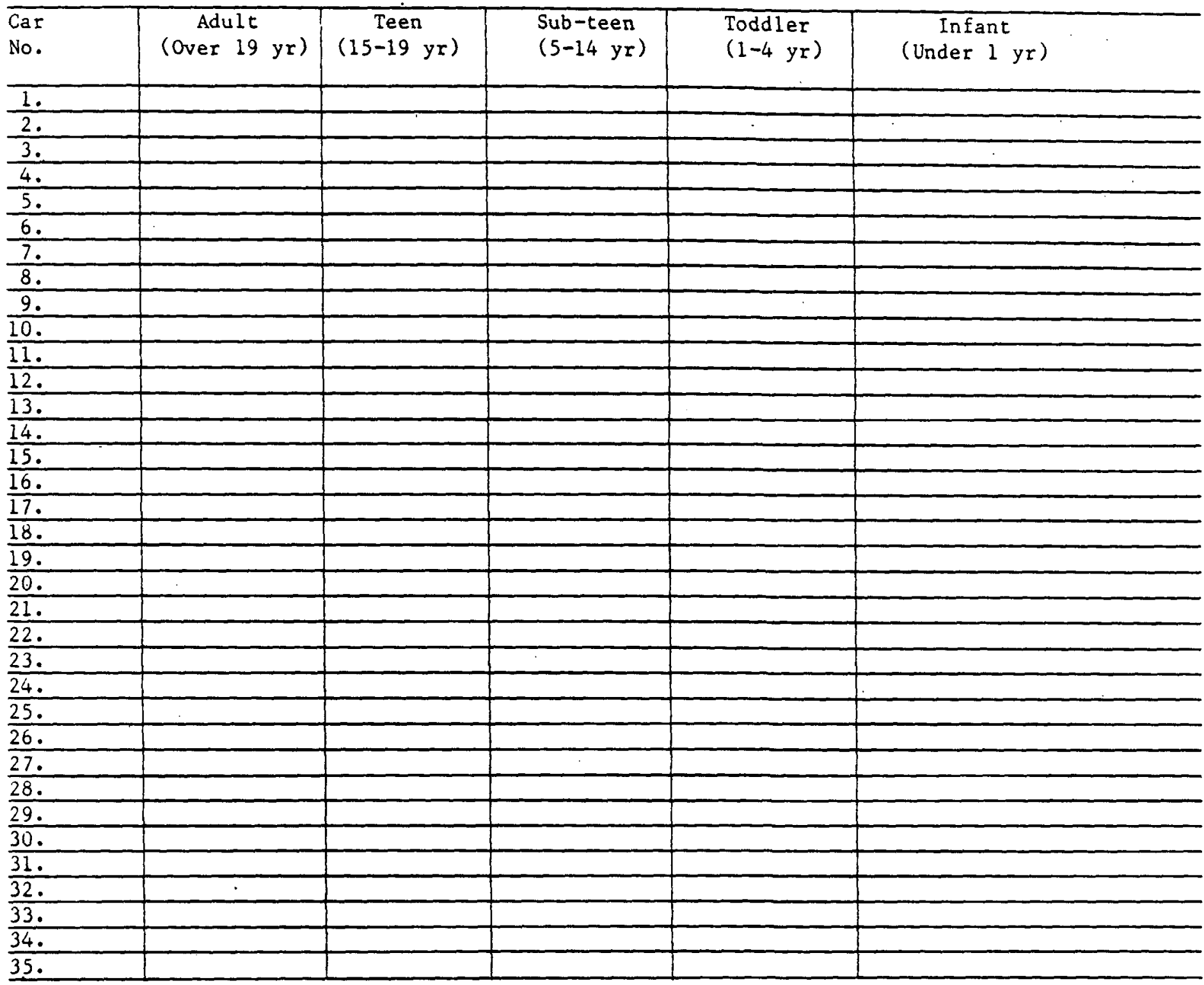

CODE FOR RESTRAINT USE:

0 . None

1. Lap/Shoulder Belt or Lap Belt Only
2. "Approved" Child Seat

3. Unsafe Seat 
6. Instructions for Filling in Passenger Survey Observation Form

\section{a. General Information}

The top portion of each form provides important information and should be completed prior to each data collection period. This information should be entered on each sheet used to collect data.

- Observer: Write in your name.

- Date: Write in the month, date, and year. For example write $7 / 4 / 83$ for July 4, 1983.

- Shopping Center Name: Write in the name of the shopping center

- Location: Fill in the name of the street closest to where data is being collected.

- Start \& End Time: Specify the hour and minutes, and circle AM or PM for the start and end of the data collection using that survey form.

b. Recording Observation Data

Complete one line on the form for each car observed. If several passengers are observed in one car, a data entry for each person all on the same line will be needed.

The data collection form has a separate column for each age category. For example, a child who looks about 3-years old, you would place the proper code number for restraint system usage under the column for "Toddlers." If you see more than one person within the same age category, you should make 2 or more entries under that age category but on the same line.

Write in the code number showing the restraint usage observed for each passenger under the proper age column.

- None (Code 0$)$

Use Code " 0 " when there is no means used to restrain the passenger who may be sitting, standing, or laying on the seat or floor. Children being held on the lap of another passenger also should be coded a " 0 ." Do not include passengers in the rear compartment of station wagons or hatch backs where there are no seats. 
$\circ$ Lap/Shoulder Belt or Lap Belt Only (Code 1)

This means that you observe the passenger wearing a safety belt, where the lap belt is across the passenger's waist or/and the shoulder harness is over the passengers shoulder. Fill in a code " 1 " under the appropriate age column.

- "Approved" Child Seat (Code 2)

You will see a large variety of child seats in the cars you will be observing. The most common ones you will see are designed for toddlers as shown in Figure-1, where the child seat has its own harness to secure the child.
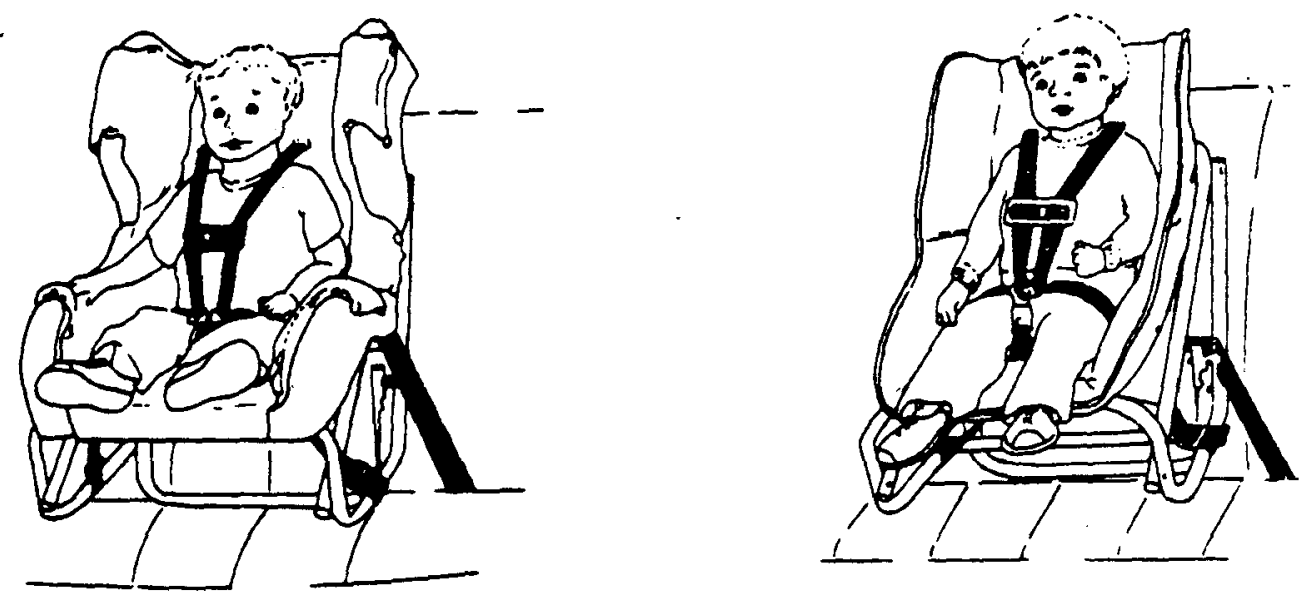

Figure 1. "Approved" Child Seats Utilizing a Safety Harness 
Some child seats utilize a combination harness and shield as shown in Figure 2 or they may incorporate a full shield as shown in Figure 3.
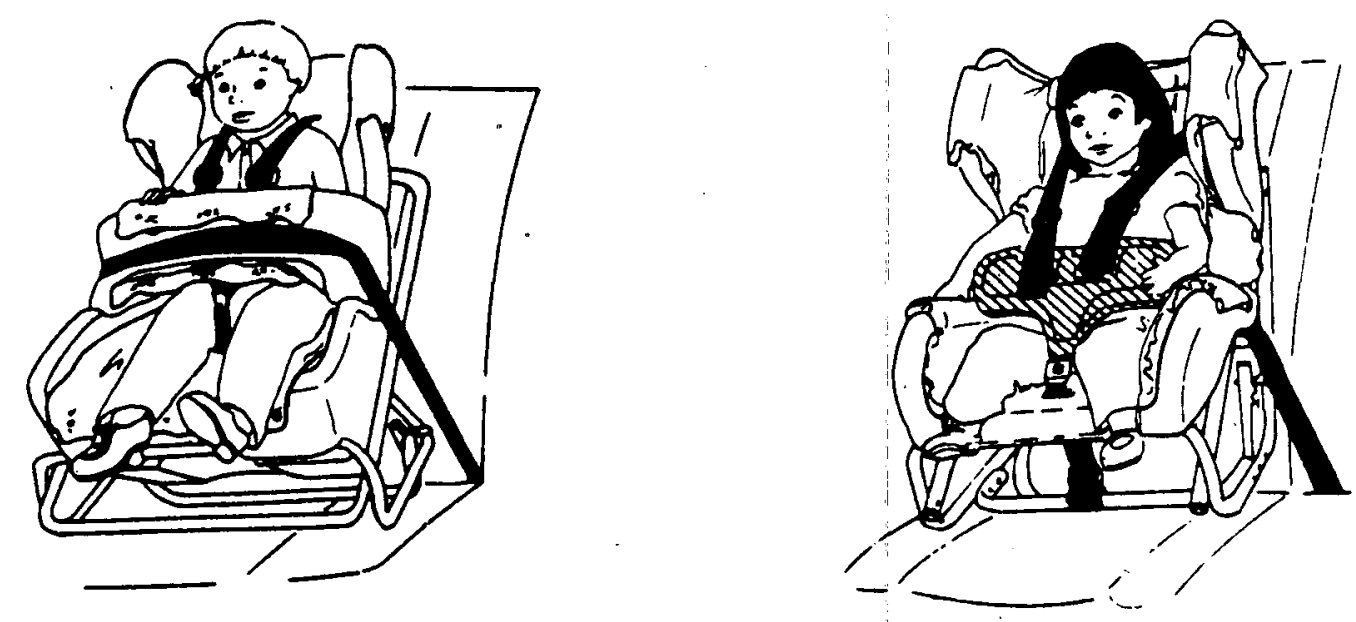

Figure 2. Child Seats Using Partial Shields and Harness
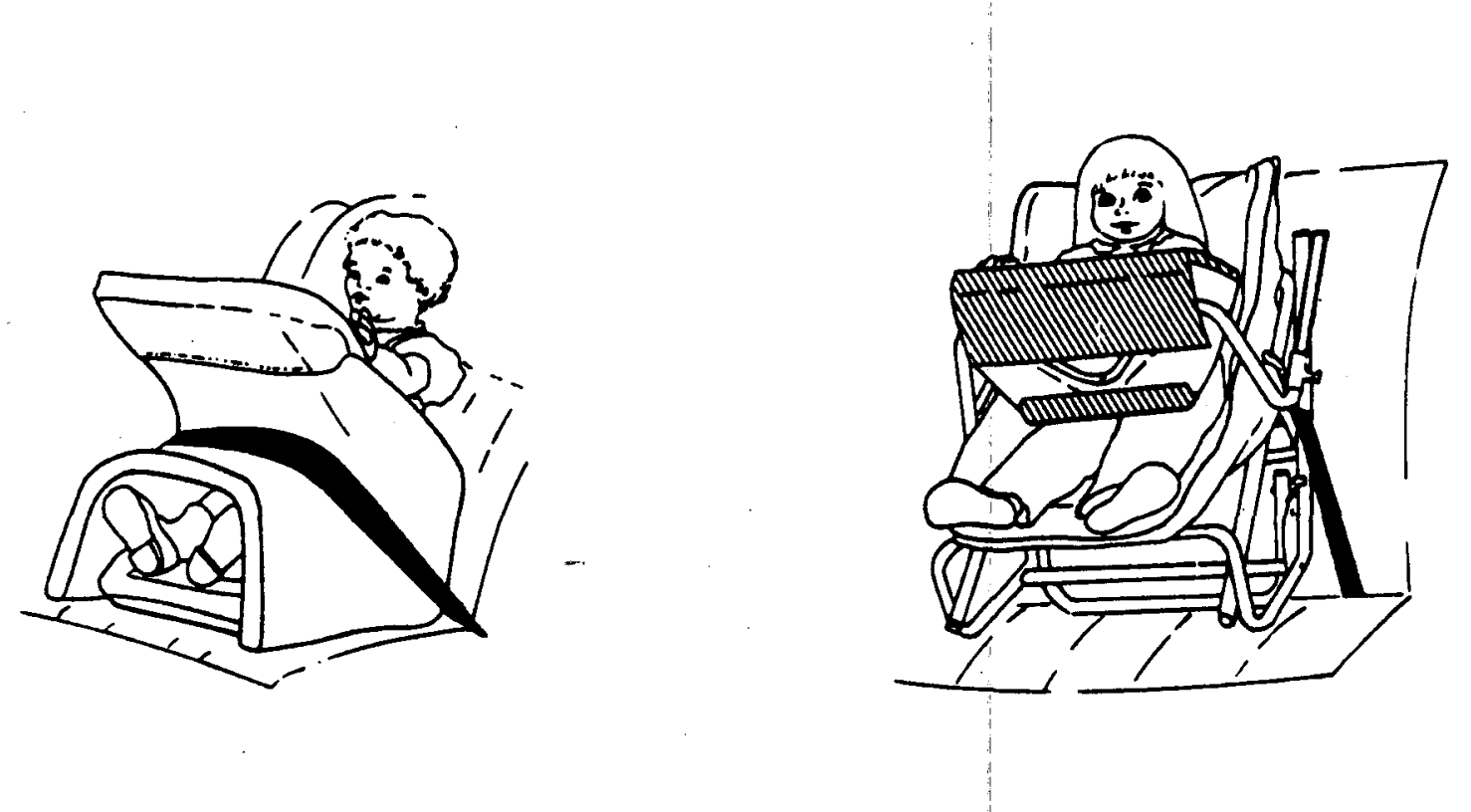

Figure 3. Child Seats With Full Shield, No Harness Required 
Many of these seats are "convertible" and can be used for either an infant or a toddler. While in the infant "position". (see Figure 4) the combination seat is positioned so the child faces rearward.
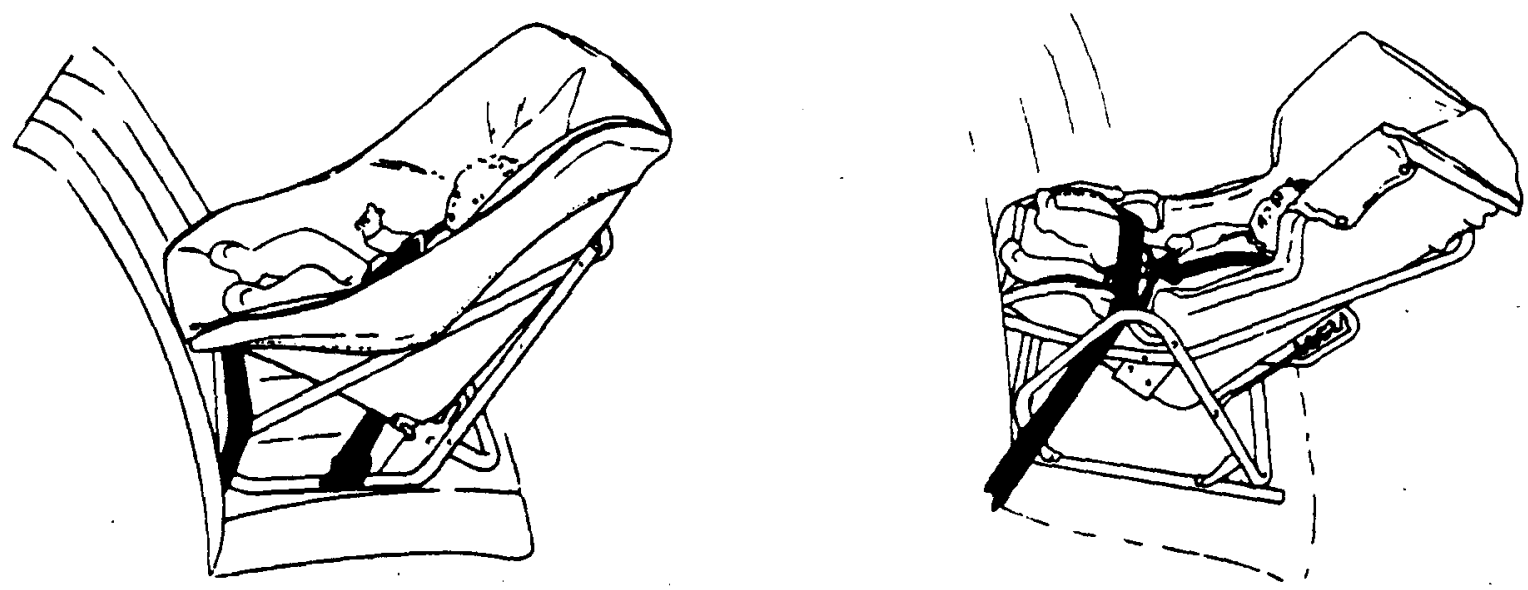

Figure 4. "Combination" Infant and Toddler Seats Shown Used in the Infant Position

There are some seats that are designed just for infants as shown in Figure 5 , and these seats are generally smaller than toddler seats.

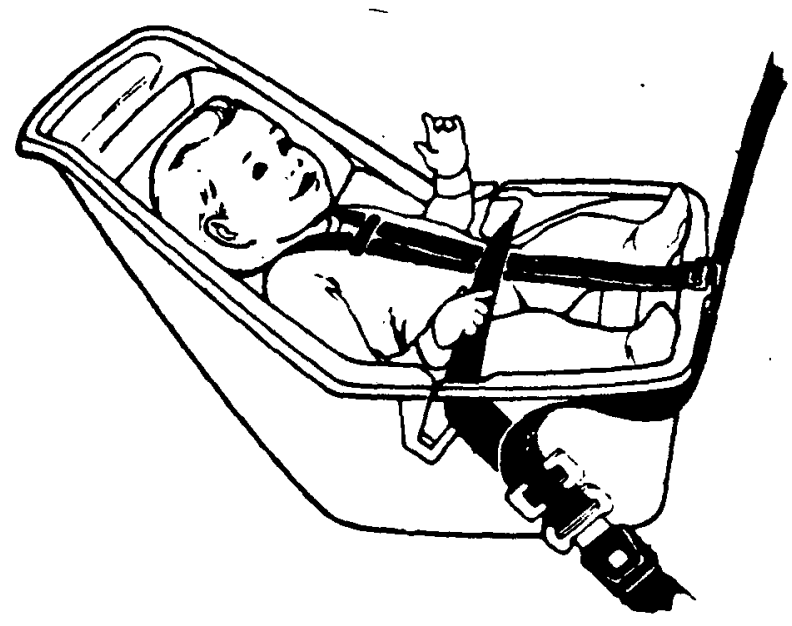

Figure 5. Infant Only Seat 
You do not have to identify the dirferent types of seats or whether or not they are being used correctly, but you should be aware of the variety of seats that you may see. However, you need to distinguish these safety type seats from the unsafe "feeder" seats designed for home use and not for use in cars. These unsafe seats are described next.

- Unsafe Seat (Code 3)

There are several types of seats that may be erroneously considered as safety seats. These seats are intended for use in the home and do not provide any protection in the event of an accident. The seats are usually made of thin plastic and equipped with straps as shown in Figure 6 . They have no provisions for attachment to the car using safety belts and were not designed to withstand the forces associated with an accident. There are also some
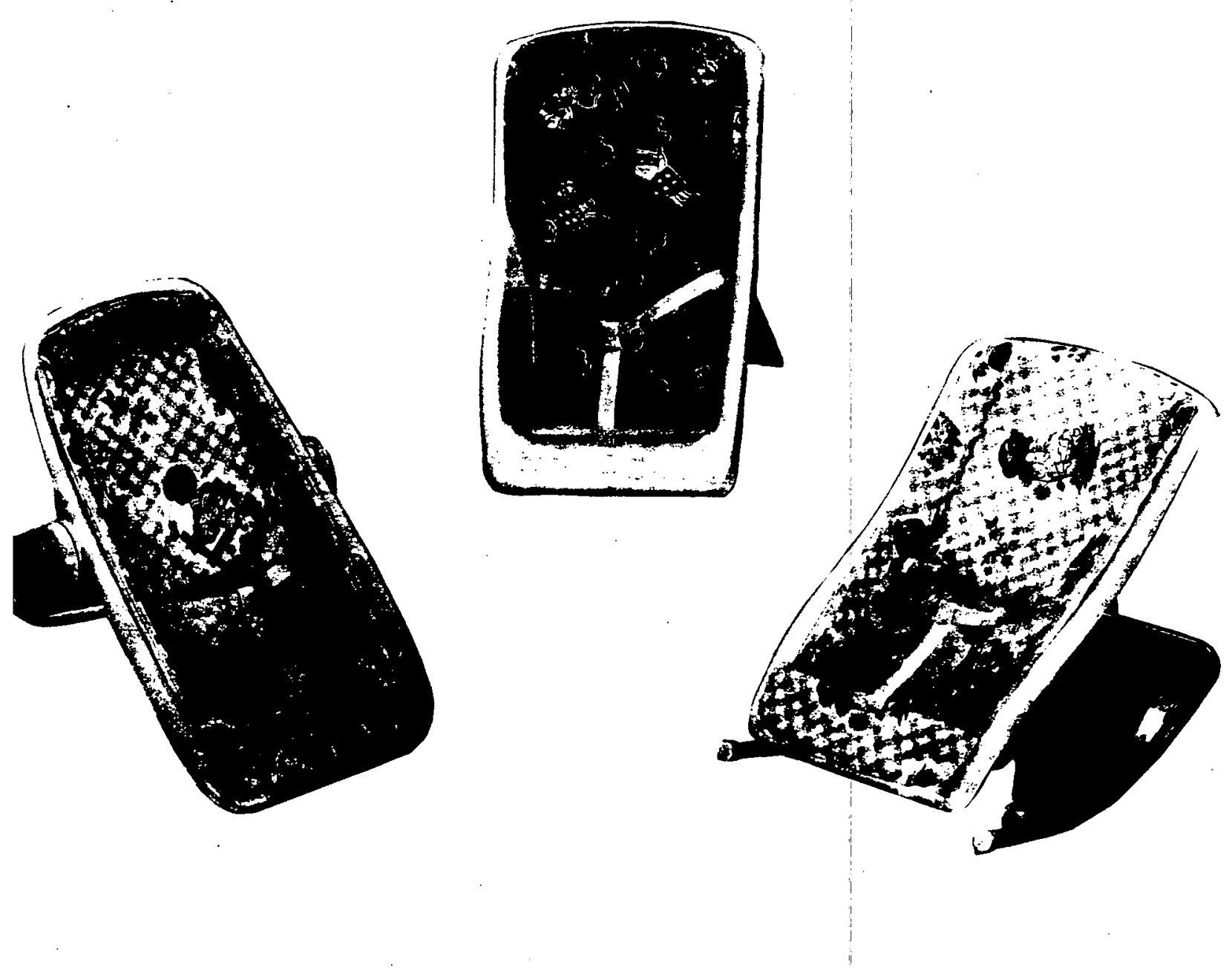

Figure 6. Child Seats Unsafe for Car Use 
older type infant/toddler seats originally designed to be used in the car which may still be used, but do not provide adequate protection in the event of a collision. Any child seat with "hooks" designed to hang over the car seat should be considered an unsafe seat. Devices such as car beds are also not acceptable as a child safety seat and should be given a Code "3."

C. Data Quality Control

Due to the importance of data accuracy and observer productivity, the supervisors will make periodic visits to observation sites. This type of activity is standard practice for most data collection efforts. During these visits the supervisors will monitor your observation techniques, answer procedural questions, and perform checks on accuracy and productivity. These visits may or may not be announced ahead of time.

The purpose of these checks will be to ensure data accuracy and improve observer performance. The visits are necessary for data validity purposes and will assure the collection of accurate and complete data. 